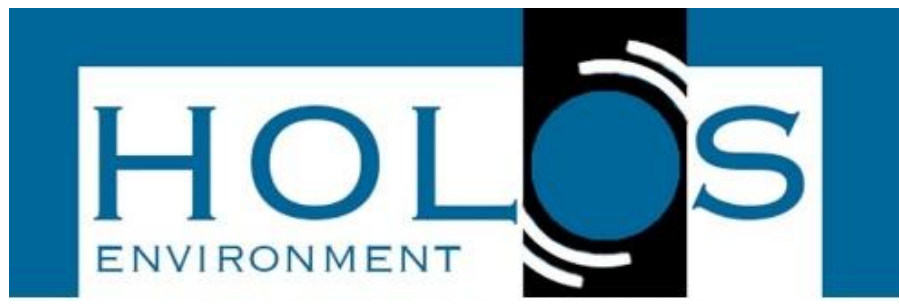

\title{
A IMPLEMENTAÇÃO DA INDC BRASILEIRA À LUZ DO ACORDO DE PARIS E SEUS DESAFIOS
}

\section{THE IMPLEMENTATION OF THE INDC BRAZILIAN IN LIGHT OF THE PARIS AGREEMENT AND ITS CHALLENGES}

\author{
Marcelo Hugo de Medeiros Bezerra ${ }^{1}$; Carlos Roberto Sanquetta ${ }^{1}$; Ana Paula Dalla \\ Corte $^{1}$; Marieli Sabrina Ruza'; Marília do Carmo Dolci de Carvalho ${ }^{1}$
}

Artigo recebido em: 16/05/2018 e aceito para publicação em: 19/03/2019.

DOI: http://dx.doi.org/10.14295/holos.v19i1.12293

Resumo: Em 2015, sob o contexto de negociações climáticas que culminou na adoção do Acordo de Paris, o Brasil apresentou sua intenção de Contribuição Nacionalmente Determinada (iNDC), que se tornou o compromisso climático de mitigação de Gases de Efeito Estufa (GEE) do país. A presente pesquisa teve como objetivo identificar os principais desafios para a implementação da meta estipulada pelo governo brasileiro. Para tanto, foram realizadas entrevistas semiestruturadas com 20 representantes da área climática, divididos em 4 segmentos: governo, sociedade civil, academia e iniciativa privada. A hipótese de que a alocação de recursos financeiros para o cumprimento das metas será crítica se confirmou, assim como, que a estrutura de governança climática e as políticas e programas atuais precisam ser atualizados para o alcance da meta. Como resultados adicionais obtidos, os setores de energia, mudança de uso da terra e florestas e agropecuária são os que precisam de uma maior atenção para cumprir os objetivos estabelecidos. Em relação à ambição, o segmento de governo acredita que a meta brasileira é bem ambiciosa, o segmento da sociedade civil atesta que a meta não é ambiciosa e deveria ser alterada, e os representantes da academia e iniciativa privada se dividiram na opinião sobre o assunto. Conclui-se que o país enfrentará diversos desafios de cunho econômico, tecnológico e de implementação da legislação e conversão da meta em políticas públicas efetivas e que a mudança do clima seja a principal diretriz para um novo modelo de desenvolvimento pautado em uma economia de baixo carbono.

Palavras-chave: Economia de Baixo Carbono. Mitigação. Mudanças Climáticas.

Abstract: In 2015, under the context of climate negotiations that culminated in the adoption of the Paris Agreement, Brazil presented its intended Nationally Determined Contribution, (iNDC), which has become the climate commitment to Greenhouse Gases mitigation in the country. This study aimed to identify the main challenges for the implementation of the goal set by the Brazilian government. For that, semi-structured interviews were conducted with 20 experienced representatives in the climate area, divided into 4 segments: government, civil society, academia and the private sector. The hypothesis that the allocation of financial resources to meet the targets will be critical was confirmed, as well as the hypothesis that climate governance structure and current policies and programs need to be updated to achieve the goal. As additional results, the sectors of energy, land use change and forests and agriculture are in need of greater attention to meet the established goals. Regarding the ambition, the segment of government believes that the Brazilian goal is very ambitious, the segment of civil society shows that the goal is not ambitious and should be changed, and representatives of academia and private sector were divided in opinion on the subject. It is concluded that the country will face several challenges of economic development, technological and implementation of legislation and the

\footnotetext{
1 Universidade Federal do Paraná (UFPR). Curitiba, PR. E-mails: (demedeiros.bezerra@gmail.com, carlos sanquetta@hotmail.com, anapaulacorte@gmail.com, marielisabrinaruza@yahoo.com.br, malia.dolci@gmail.com)
} 
conversion of the goal into effective public policy and that climate change must be the main guideline for a new development model based in a low-carbon economy.

Palavras-chave: Low-Carbon Economy. Mitigation. Climate Change.

\section{INTRODUÇÃO}

As mudanças climáticas são um problema global, de longo prazo e possuem impactos nos mais diversos segmentos da sociedade, além do fato de que uma resposta adequada ao problema está inserida em um ambiente de incerteza e riscos (GIDDENS, 2010). Para tratar de tal problema, os países vêm conduzindo, nas últimas três décadas, negociações internacionais visando o estabelecimento de instrumentos jurídicos internacionais para tentar combater a questão de maneira efetiva em escala global.

Com o estabelecimento do Acordo de Paris em 2015, cada país participante da UNFCCC (Convenção-Quadro das Nações Unidas sobre Mudanças Climáticas) submeteu uma iNDC com suas respectivas ações para combater as mudanças climáticas e com sua meta de redução de emissão de GEE (UNFCCC, 2015). O Brasil comprometeu-se a reduzir as emissões de GEE em 37\% abaixo dos níveis de 2005, em 2025, e de $43 \%$ abaixo dos níveis de 2005, em 2030, a partir da apresentação da "Contribuição indicativa subsequente".

Juntamente com a iNDC o Brasil encaminhou um anexo apresentando medidas adicionais, porém, sem obrigação legal em atingi-las. Entre os destaques: Alcançar o desmatamento ilegal zero até 2030 na Amazônia brasileira; Restaurar e reflorestar 12 milhões de hectares de florestas até 2030; Alcançar uma participação estimada de $45 \%$ de energias renováveis na composição da matriz energética em 2030; Fortalecer o Plano de Agricultura de Baixa Emissão de Carbono (Plano ABC), com restauração adicional de 15 milhões de hectares de pastagens degradadas e incremento de 5 milhões de hectares de sistemas de integração lavoura-pecuáriaflorestas até 2030.

Embora tenha alcançado resultados expressivos na redução das emissões na década passada, o Brasil vem demonstrando, nos últimos anos, certo aumento de emissões em setores importantes (OBSERVATÓRIO DO CLIMA, 2014). Esta nova configuração das emissões traz desafios relevantes, pois as opções de mitigação mais baratas já foram esgotadas (controle de grande parte do desmatamento) e no- 
vas e expressivas reduções exigirão a capacidade em todos os níveis de governo para elaborar e implementar políticas públicas climáticas articuladas (VIOLA et al., 2013).

Portanto, diante do exposto, o objetivo do presente trabalho é identificar os principais desafios na implementação da iNDC do Brasil, indicando quais os setores e áreas-chave da economia e sociedade brasileira que são determinantes para lograr as metas propostas, além de avaliar se a iNDC do Brasil atende ao critério de máxima ambição estabelecido no Acordo de Paris.

\section{MATERIAL E MÉTODOS}

O presente trabalho caracteriza-se como uma pesquisa qualitativa, visto que os dados foram obtidos através do contato direto e interativo dos pesquisadores com a situação objeto de estudo, sendo a interpretação do fenômeno estudado resultante das perspectivas dos participantes em relação à situação observada (NEVES, 1996).

A partir deste trabalho, pretendeu-se identificar e analisar os principais desafios para alcançar os objetivos e metas propostas na iNDC do Brasil, submetida à UNFCCC em 2015 no processo para a definição do novo acordo mundial climático estabelecido na COP 21, em Paris. Esta pesquisa se caracteriza, portanto, como exploratória descritiva (TRIPODI et al., 1981), um subtipo de estudo de caso (BRUYNE, 1991), pois já foram submetidas mais de 150 iNDCs à UNFCCC pelos seus respectivos países e o presente trabalho analisa somente a iNDC do Brasil, não realizando qualquer análise comparativa com as outras iNDCs. Também se ressalta que foi analisado somente o tema de mitigação referente à iNDC brasileira, não sendo matéria de análise o conteúdo sobre adaptação, direitos humanos, bem como outras temáticas.

Para tanto, foram realizadas entrevistas semiestruturadas com representantes de quatro segmentos da sociedade brasileira e que exercem atividades ligadas às mudanças climáticas no Brasil, sejam ligadas às negociações internacionais ou políticas ambientais (Tabela 1). Os quatro segmentos que compreendem a população da pesquisa são: governo federal, sociedade civil organizada, instituições acadêmicas e o setor privado. 
Tabela 1 - Entrevistados na pesquisa, representantes dos segmentos da sociedade e sua função ou cargo

\begin{tabular}{|c|c|c|}
\hline SEGMENTO & NOME & CARGO/FUNÇÃO \\
\hline Governo Federal & Everton Lucero & $\begin{array}{l}\text { Secretário de Mudanças Climáticas e Qualidade Ambi- } \\
\text { ental do Ministério do Meio Ambiente }\end{array}$ \\
\hline Governo Federal & Adriano Santiago & $\begin{array}{l}\text { Diretor de Mudanças Climáticas do Ministério do Meio } \\
\text { Ambiente }\end{array}$ \\
\hline Governo Federal & Felipe Ferreira & Chefe da Divisão de Clima do Itamaraty \\
\hline Governo Federal & Letícia Guimarães & $\begin{array}{c}\text { Gerente de Mudança do Clima e Florestas do Ministério } \\
\text { do Meio Ambiente }\end{array}$ \\
\hline Governo Federal & Aloisio Melo & $\begin{array}{l}\text { Coordenador-Geral de Meio Ambiente e Mudanças Cli- } \\
\text { máticas da Secretária de Política Econômica do Ministé- } \\
\text { rio da Fazenda }\end{array}$ \\
\hline Sociedade Civil & Carlos Rittl & Secretário Executivo do Observatório do Clima \\
\hline Sociedade Civil & André Nahur & $\begin{array}{c}\text { Coordenador do Programa de Mudanças Climáticas e } \\
\text { Energia da WWF Brasil }\end{array}$ \\
\hline Sociedade Civil & Fernanda Bortolotto & $\begin{array}{c}\text { Pesquisadora do Instituto de Pesquisas Ambiental da } \\
\text { Amazônia (IPAM) }\end{array}$ \\
\hline Sociedade Civil & Marina Piatto & $\begin{array}{c}\text { Coordenadora da iniciativa de Clima e Cadeias } \\
\text { Agropecuárias do Instituto de Manejo e Certificação } \\
\text { Florestal e Agrícola (IMAFLORA) }\end{array}$ \\
\hline Sociedade Civil & Pedro Telles & $\begin{array}{c}\text { Coordenador de projetos de Clima e Energia do } \\
\text { Greenpeace Brasil }\end{array}$ \\
\hline Setor Acadêmico & Mariana Xavier Nicolletti & $\begin{array}{l}\text { Gestora de Projetos do Centro de Estudos em Sus- } \\
\text { tentabilidade da Fundação Getúlio Vargas }\end{array}$ \\
\hline Setor Acadêmico & Alexandre Araújo Costa & Professor Titular da Universidade Estadual do Ceará \\
\hline Setor Acadêmico & Paulo de Tarso & $\begin{array}{c}\text { Professor Adjunto da Universidade Federal do Para- } \\
\text { ná }\end{array}$ \\
\hline Setor Acadêmico & Rafaelo Balbinot & $\begin{array}{l}\text { Professor Adjunto e Chefe do Departamento de En- } \\
\text { genharia Florestal da Universidade Federal de Santa } \\
\text { Maria }\end{array}$ \\
\hline Setor Acadêmico & Carlos Lima & $\begin{array}{l}\text { Professor Adjunto da Universidade Federal de Cam- } \\
\text { pina Grande }\end{array}$ \\
\hline Setor Privado & Roberto Waac & Sócio-Fundador da AMATA \\
\hline Setor Privado & João Adrien & Diretor Executivo da Sociedade Rural Brasileira \\
\hline Setor Privado & Carlo Pereira & $\begin{array}{l}\text { Gerente Corporativo de Sustentabilidade da CPFL } \\
\text { Energia }\end{array}$ \\
\hline Setor Privado & Luiz Carlos & $\begin{array}{c}\text { Coordenador de Desenvolvimento Sustentável da } \\
\text { Braskem }\end{array}$ \\
\hline Setor Privado & Willian Kimura & Pesquisador da AGROICONE \\
\hline
\end{tabular}

Devido à grande quantidade de instituições pertencentes a esses quatro segmentos, bem como, considerando as limitações deste trabalho, para viabilizar a qualidade e relevância do estudo foram escolhidos como amostra de pesquisa 5 representantes de cada segmento que possuem alguma experiência acadêmica e profissional relevante na área de mudanças climáticas e política ambiental, além de exer- 
cerem atividades profissionais que estão diretamente ligadas ao objeto de estudo. É de suma importância ressaltar que a opinião coletada é do entrevistado e não necessariamente reflete a opinião da instituição em que ele exerce função atualmente.

O processo de coleta de dados se deu no período de Julho a Setembro de 2016 e contemplou as seguintes etapas: a) pesquisa bibliográfica sobre a literatura; b) Pesquisa qualitativa documental e elaboração do roteiro da entrevista semiestruturada c) realização das entrevistas semiestruturadas com os representantes dos segmentos listados acima; d) transcrição e posterior análise qualitativa das entrevistas com o intuito de alcançar os objetivos da pesquisa.

Para a análise das entrevistas, adotou-se o método da análise de conteúdo (BARDIN, 1994) que se divide em 3 etapas: 1) pré-análise: organização do material a ser analisado, bem como outros materiais que podem ajudar a entender melhor 0 fenômeno a ser estudado; 2) descrição analítica: aprofundamento do material coletado, orientado pelas hipóteses e referencial teórico, buscando convergências e divergências de ideias; 3) interpretação referencial: análise e categorização final, usando-se da reflexão e intuição, além do embasamento em materiais empíricos, estabelecendo relações com a realidade.

O método de análise de conteúdo foi adotado pela sua facilidade em compreender a realidade do ponto de vista dos entrevistados a partir do seu discurso, permitindo ao pesquisador um melhor entendimento das representações que o entrevistado possui em relação à sua realidade e de como ele interpreta os fenômenos a sua volta, sendo tal método predominante nas pesquisas qualitativas (SILVA et al., 2005).

\section{RESULTADOS E DISCUSSÕES}

A partir das opiniões obtidas pelas entrevistas realizadas, seguida da análise de conteúdo, foram definidas cinco categorias: Desafios de implementação; Políticas, Programas e Legislação de Clima; Setores-chave para o alcance da meta; Instrumentos econômicos e tributários; Ambição.

\subsection{Desafios de implementação}

Para a categoria desafios da implementação os 20 entrevistados citaram os 
principais desafios em nível "macro" para a implementação de ações visando atingir a meta da iNDC (Tabela 2). Somente dois desafios foram citados por pelo menos um representante dos quatro segmentos: "Falta de Recursos Econômicos" e "Melhoria da Governança Climática”.

Tabela 2 - Principais desafios para alcance da meta da iNDC brasileira citados pelos entrevistados dos diferentes segmentos da sociedade

\begin{tabular}{ccccccc}
\hline Desafios na implementação da iNDC & Governo & ONGs & Privado & Academia & Total & $\%$ \\
\hline Contenção do desmatamento & 1 & 1 & 0 & 2 & 4 & $20 \%$ \\
Panorama político/econômico & 0 & 2 & 1 & 3 & 6 & $30 \%$ \\
Política energética do país & 0 & 1 & 2 & 1 & 4 & $20 \%$ \\
Falta de Recursos Econômicos & 3 & 1 & 3 & 4 & 11 & $55 \%$ \\
Coesão Social & 5 & 0 & 3 & 1 & 9 & $45 \%$ \\
Melhoria da Governança Climática & 4 & 2 & 1 & 2 & 9 & $45 \%$ \\
\hline
\end{tabular}

Para mais da metade dos entrevistados, a implementação de ações para atingir a meta principal e para o alcance das metas de meios de implementação propostas no anexo da iNDC vão requerer volumes consideráveis de recursos financeiros. A conversão da meta da iNDC em políticas e programas específicos, terá sua viabilidade prática somente se houver dotação orçamentária ou um fluxo de recursos financeiros contínuos e voltados para as mudanças climáticas no país.

Pela análise das entrevistas dos representantes dos segmentos da sociedade civil, academia e iniciativa privada pôde-se vincular esse desafio da "Falta de Recursos Econômicos" com o "Panorama Político/Econômico" e "Política Energética do País", visto que a atual situação de crise vivenciada pelo país poderá tirar a pauta de clima do centro da estratégia do governo. Já a política energética foi citada como uma grande direcionadora de recursos econômicos e incentivos fiscais para a indústria energética fóssil e tal situação precisa mudar caso o Brasil queira atingir o compromisso estabelecido na iNDC.

A "Melhoria da Governança Climática" foi outro desafio citado pelos 4 segmentos, sendo considerada essencial pela necessidade de adaptar a estrutura existente para uma melhor eficácia na elaboração e implementação das iniciativas. Os próprios representantes do governo federal reconhecem essa necessidade e acreditam que seja importante uma revisão da Política Nacional de Mudança do Clima (PNMC) e que seja adotada uma visão mais holística da temática no país. 
Outro ponto de destaque nos desafios foi o item "Coesão Social", na qual os entrevistados reconhecem que a meta da iNDC só será implementada, se todos os atores colaborarem em conjunto na definição e implementação das políticas e programas. Fazendo uma relação desse desafio com o de "Melhoria da Governança Climática", é primordial que seja criada uma estrutura que ajude a integrar a diversidade de grupos que são importantes para a política de clima no país, na qual cada segmento necessita expor sua visão e seus desafios.

\subsection{Políticas, Programas e Legislação de Clima}

Neste quesito, todos os 20 entrevistados, consideraram que as políticas e programas atuais precisam passar por uma reavaliação, mas principalmente que existem certas lacunas que deverão ser preenchidas com novas políticas para refletir a nova dinâmica do Acordo de Paris e da meta adotada na iNDC.

Para os membros do governo, existe a necessidade de readequação das políticas, programas e principalmente da PNMC, tendo em vista que os planos setoriais e a PNMC foram criados no contexto em que os países em desenvolvimento possuíam metas voluntárias.

Os entrevistados da sociedade civil deram respostas alinhadas com a dos representantes do governo federal no sentido de que existe a necessidade de que as mudanças climáticas sejam um elemento estruturante de outras políticas públicas. Para esse segmento, as políticas e programas atuais não são suficientes, pois ou não são implementados na íntegra e no prazo correto ou não recebem os investimentos necessários para surtir um efeito considerável de mitigação.

Para a iniciativa privada, falta uma política clara e objetiva de desenvolvimento tecnológico para atividades de baixo carbono, além da falta de alocação de recursos financeiros adequados. As políticas e programas existentes são mais como diretrizes setoriais, além do que falta uma participação mais forte e efetiva da iniciativa privada e sociedade civil na construção e implementação dessas políticas.

Os representantes do setor acadêmico destacaram a falta da implementação efetiva de programas atuais que poderiam causar grande impacto, como o Plano $A B C$ e o Cadastro Ambiental Rural (CAR). Foi unânime a consideração de que a grande lacuna é na implementação da legislação e não na formulação e regulação da legislação. 
Um ponto bastante mencionado pelos setores da academia, sociedade civil e iniciativa privada é em relação às políticas que o governo vem adotando nos últimos anos e que não são compatíveis com uma economia de baixo carbono, principalmente no setor energético. Os investimentos prioritários para a indústria fóssil por meio de subsídios, com o consequente efeito negativo para a indústria de etanol, ao mesmo tempo em que as novas hidroelétricas na região Amazônica e as novas termoelétricas têm um impacto socioambiental enorme, não só relacionado à emissão de GEE.

Outro quesito importante relacionado à legislação e políticas públicas levantadas por representante da sociedade civil foi a importância das Terras Indígenas (TIs) na contribuição da mitigação climática no país, pois apesar da de reconhecer o papel das TIs nas remoções de GEEs, não há nenhum compromisso específico em garantir a segurança da posse de áreas florestais indígenas na iNDC. Segundo WRI (2016), entre 2000 e 2012, a taxa de desmatamento dentro de áreas florestais indígenas de posse segura no Brasil foram 2,5 vezes menor que aquelas de fora dessas áreas, sendo a demarcação das Tls uma estratégia eficaz para a redução do desmatamento na Amazônia (IPAM, 2015), além de ser uma medida de baixos custos e com benefícios socioeconômicos.

\subsection{Setores-chave para o alcance da meta}

De acordo com as entrevistas, três setores são considerados cruciais para a tomada de decisão e adoção de políticas específicas para reduzir progressivamente as reduções de GEE do país: Energia, Florestas e mudança de uso da terra e Agropecuária (Tabela 3). Tal resultado é esperado, visto que os três setores vêm dominando e dividindo a maior parcela das emissões de GEE nos últimos anos, representando cada um cerca de 30\% no perfil brasileiro de emissões em 2012 (OBSERVATÓRIO DO CLIMA, 2014). 
Tabela 3 - Setores-chave mencionados para o alcance da meta da iNDC brasileira por cada segmento entrevistado

\begin{tabular}{ccccccc}
\hline Setores-chave & Academia & Governo & Privado & Sociedade Civil & TOTAL & $\%$ \\
\hline Energia & 5 & 5 & 5 & 5 & 20 & $100 \%$ \\
Florestas & 5 & 5 & 5 & 5 & 20 & $100 \%$ \\
Agropecuária & 4 & 5 & 3 & 5 & 17 & $85 \%$ \\
Resíduos & 1 & 0 & 0 & 1 & 2 & $10 \%$ \\
Indústria & 3 & 1 & 2 & 2 & 8 & $40 \%$ \\
\hline
\end{tabular}

O setor Florestal e mudança de uso da terra sofreram várias oscilações nas emissões nos últimos anos, pois após a grande redução do desmatamento no período 2005-2009 o processo de redução foi interrompido em 2012, tendendo à estagnação (YOUNG, 2016), mas as taxas de desmatamento voltaram a crescer em 2013 e depois caíram em 2014 chegando ao ponto mais baixo da série histórica (OBSERVATÓRIO DO CLIMA, 2016).

Contudo, o relatório do INPE (2016a) utilizando dados do Prodes 2015 (Projeto de Monitoramento do Desmatamento na Amazônia Legal) mostra que o desmatamento na Amazônia Legal de agosto de 2014 a julho de 2015 representou 6.207 $\mathrm{km}^{2}$, crescendo $24 \%$ em relação à taxa do período anterior. Para o período entre agosto de 2015 e julho de 2016 houve um novo aumento do desmatamento, com a estimativa oficial de 7.989 km² de área desmatada na Amazônia (INPE, 2016b). Essa oscilação e o retorno do crescimento do desmatamento indicam que é necessária a revisão das políticas e mecanismos existentes, corroborando com as opiniões dos entrevistados de que a redução do desmatamento ainda será bastante desafiadora.

O setor florestal respondeu por $42 \%$ das emissões brutas do país, sendo o principal setor emissor (OBSERVATÓRIO DO CLIMA, 2016), embora a conversão de florestas para outros usos esteja ligada à forte expansão da fronteira agropecuária e as grandes obras de infraestrutura no país, não necessariamente representando as atividades do setor de base florestal. O setor agropecuário foi mencionado por $85 \%$ dos entrevistados, por ser a principal atividade causadora do desmatamento/mudança de uso do solo, principalmente na Amazônia e por não ter ainda medidas eficazes concretas e em escala nacional para aumentar a eficiência no setor, tanto do ponto de vista da produção pecuária quanto para o pequeno agricultor no campo. O setor agropecuário é atualmente o terceiro maior emissor considerando as 
emissões brutas e o segundo maior emissor considerando emissões líquidas (OBSERVATÓRIO DO CLIMA, 2016).

O setor de energia foi considerado o mais preocupante pela maioria dos entrevistados, pois no setor florestal já existem mecanismos de comando e controle, diferentemente do setor energético no qual ainda existem muitos subsídios governamentais para atividades carbono-intensivos, como termoelétricas e para a indústria automotiva, além de não haver incentivos adequados para as energias renováveis segundo os entrevistados da academia, iniciativa privada e sociedade civil.

De acordo com o Balanço Energético Nacional 2016 - ano base 2015, o total das emissões antrópicas do setor energético em 2015 atingiu 462,34 MtCO2.eq, com uma projeção de aumento das emissões em 2020, chegando a 502 MtCO2.eq. (EPE, 2016). O setor energético já é o principal setor emissor do país atualmente (OBSERVATÓRIO DO CLIMA, 2016), sendo necessárias mudanças significantes nas atuais políticas energéticas caso o Brasil pretenda alcançar a meta estabelecida na iNDC (PASQUAL et al., 2016).

O setor industrial recebeu uma quantidade significativa de menções (40\%) por ser um grande consumidor de combustíveis fósseis e energia elétrica nos seus processos, além de não possuir programas adequados para o desenvolvimento tecnológico e de medidas específicas de mitigação na escala necessária. O setor de resíduos foi mencionado, como um setor que tem um potencial subaproveitado para reduzir as emissões e que inclusive poderia gerar retornos econômicos, como o aproveitamento do biogás.

\subsection{Instrumentos econômicos e tributários}

Houve um consenso entre os entrevistados, pois todos os 20 profissionais acreditam que existe a necessidade de criação de instrumentos econômicos e de tributação (Tabela 4), não só para o alcance da meta, como também para impulsionar os setores-chave em direção a uma economia de baixo carbono. 
Tabela 4 - Principais instrumentos econômicos a serem criados que foram citados pelos entrevistados por cada segmento da sociedade avaliado

\begin{tabular}{ccccccc}
\hline Instrumento/política econômica & academia & governo & privado & ONG & Total & $\%$ \\
\hline Precificação do carbono & 2 & 4 & 2 & 4 & 12 & $60 \%$ \\
Fim do subsídio aos fósseis & 1 & 0 & 1 & 1 & 3 & $15 \%$ \\
Sistema cap and trade & 1 & 0 & 0 & 3 & 4 & $20 \%$ \\
Linhas de financiamento & 2 & 0 & 1 & 3 & 6 & $30 \%$ \\
Tributação favorável às renováveis & 3 & 1 & 3 & 2 & 9 & $45 \%$ \\
Subsídios para florestas & 2 & 1 & 0 & 1 & 4 & $20 \%$ \\
\hline
\end{tabular}

Caso o Brasil realmente se comprometa em atingir as metas do anexo da iNDC, os investimentos necessários serão da ordem de bilhões de reais. O Instituto Escolhas (2016) calculou que para recuperar 12 milhões de hectares de florestas até 2030 serão necessários entre $R \$ 31$ bilhões e $R \$ 51$ bilhões, dependendo dos cenários de modelo de recuperação florestal escolhido, representando investimentos entre $R \$ 2,2$ bilhões e $R \$ 3,7$ bilhões por ano.

O GVces (2016) realizou uma análise econômico-financeira do cumprimento das metas estabelecidas no Plano $A B C$ e na iNDC brasileira de recuperar $30 \mathrm{mi}-$ Ihões de hectares de pastagens degradadas e da adoção de 9 milhões de hectares de sistemas integrados de produção, somados os dois compromissos. Como resultado, obteve-se que para a recuperação de pastagens degradadas a atividade não é economicamente viável para o produtor rural, pois o cálculo do Valor Presente seria negativo entre $R \$ 28,59$ bilhões e $R \$ 15,75$ bilhões. Para os sistemas integrados Pecuária-Floresta, o Valor presente ficaria entre $R \$ 150$ milhões negativos e $R \$ 4$ bilhões positivos. Tais números refletem a necessidade de aporte financeiro considerável pelo governo para o alcance de tais metas e para garantir a viabilidade da adoção dessas técnicas pelo setor privado.

Em relação aos custos econômicos para zerar o desmatamento no país, um estudo realizado por Young (2016), estima que seriam necessários $R \$ 5,2$ bilhões por ano em um horizonte de 15 anos para alcançar tal finalidade por meio de uma política de Pagamentos por Serviços Ambientais (PSA). O estudo também calculou que o preço mínimo da tonelada de carbono que seria capaz de zerar o desmatamento no país deveria ser de $\mathrm{R} \$ 50$ por tCO2.eq. O ponto mais importante desse estudo para balizar políticas e programas de mitigação no Brasil é que "os custos de recuperação florestal são significantemente superiores aos de conservação, indican- 
do que evitar o desmatamento é muito mais barato do que recompor a floresta depois de destruída" (YOUNG, 2016).

A precificação de carbono foi o instrumento econômico mais citado pelos entrevistados, tanto no sentido de "taxação de carbono" quanto na ideia de incentivos tributários para atividades e setores de "baixo carbono". O Pagamento por Serviços Ambientais, o ICMS Ecológico e o ITR Verde (Imposto Territorial Rural) foram instrumentos citados somente pela iniciativa privada e poderiam ser parte importante para a aceleração do processo de desenvolvimento de iniciativas de baixo carbono em setores específicos.

O desenho da elaboração desses instrumentos necessita da integração dos quatros segmentos, pois a academia e a sociedade civil possuem expertise na temática e a iniciativa privada será a maior impactada economicamente independente do instrumento a ser adotado. Portanto, é necessário que o governo federal forneça espaço para esses setores da sociedade com o intuito de exporem suas visões e necessidades. Pelas opiniões expostas, evidencia-se a necessidade de criação de instrumentos econômicos e tributários específicos para a peculiaridade de cada setor econômico e que seja adotado um conjunto desses instrumentos e não apenas um especificamente.

\subsection{Ambição da iNDC}

No que diz respeito à equidade e ambição, a parte anexa afirma que o Brasil já reduziu, em 2012, 41\% das suas emissões comparadas com os níveis de 2005. Ou seja, tecnicamente o país já alcançou o compromisso estipulado para 2025 (reduzir em 37\% com base em 2005), tanto é que o documento afirma que "se reconhece que as emissões crescerão com vistas a atender as necessidades sociais e de desenvolvimento" (BRASIL, 2015). Apesar disso, o documento atesta que a iNDC é ambiciosa, pois representa uma progressão, tanto no tipo quanto no nível de ambição, em relação aos compromissos voluntários pré-2020.

O documento apresenta como outros pontos de ambição o fato de que haverá redução de emissões em um contexto de aumento contínuo da população e do PIB, além do que os esforços de mitigação apresentados são no mínimo equivalentes em forma, escopo e escala às contribuições dos países desenvolvidos e que portanto, a iNDC apresentada é "muito mais ambiciosa do que corresponderia à responsabilida- 
de marginal relativa do Brasil ao aumento da temperatura média global" (BRASIL, 2015).

A análise se a iNDC do Brasil representava o máximo de ambição possível foi a categoria que apresentou a maior divisão entre as opiniões dos entrevistados, em que os resultados mostram que 9 entrevistados consideram a iNDC do Brasil ambiciosa, ao passo que 11 entrevistados não a consideram ambiciosa (Tabela 5).

Tabela 5 - Resultado sobre a ambição da iNDC por cada segmento entrevistado

\begin{tabular}{ccccccc}
\hline iNDC AMBICIOSA & Governo & Privado & ONG & Academia & Total & $\%$ \\
\hline SIM & 5 & 2 & 0 & 2 & 9 & $45 \%$ \\
NÃO & 0 & 3 & 5 & 3 & 11 & $55 \%$ \\
\hline
\end{tabular}

Para os representantes do governo, o estabelecimento de uma meta absoluta para o conjunto da economia foi bem ambicioso e factível, considerando o fato de que o Brasil é um país em desenvolvimento. Também ressaltaram que a iNDC quando foi proposta levou em consideração estudos e especialistas em modelagem para garantir que a meta fosse baseada na realidade do país. Os representantes do setor privado e da academia que concordam que a meta da iNDC é ambiciosa justificaram pelo contexto político e econômico turbulento que o país vivencia; as metas de implementação estabelecidas na iNDC; além da necessidade de recursos/investimentos e de uma mudança na matriz econômica que a meta impõe.

Para os representantes da sociedade civil organizada, a iNDC do Brasil não é ambiciosa. De acordo com a meta proposta na iNDC, o país vai basicamente manter as emissões dos níveis atuais, ou seja, em termos de ambição real ou de fato adicional a meta não é ambiciosa. Os representantes recordam que o Observatório do Clima apresentou uma proposta de iNDC em que o Brasil deveria limitar sua emissão de GEE em 1 GtCO2.eq em 2030 e apresentou meios de como chegar nessa meta de forma factível, além do que, de acordo com este relatório, caso o Brasil realize as ações propostas no anexo da iNDC as emissões atingiriam cerca de 1,047 GtCO2.eq em 2030 (OBSERVATÓRIO DO CLIMA, 2016). Os representantes da academia e do setor privado que concordam que a iNDC não é ambiciosa também ressaltaram que a meta global estabelecida de 37\% de redução comparada ao ano de 2005 não é difícil de atingir, e que já seria alcançada somente por meio de medidas custo-efetivas ou retirando as barreiras ainda existentes para viabilizar ações de 
mitigação. A necessidade de alterar a iNDC para adequá-la aos novos dados do $3^{\circ}$ inventário de emissões de GEE do Brasil e ao novo limite de temperatura de 1,5ㄷ indicado pelo Acordo de Paris, foram pontos bastante destacados também.

A avaliação da ambição das iNDCs é de extrema importância, visto que o próprio texto da Decisão do Acordo de Paris reconhece que os níveis de emissão agregado das iNDCs submetidas não são compatíveis com um cenário de aumento de até $2{ }^{\circ} \mathrm{C}$ de temperatura em relação aos níveis pré-industriais e, além disso, direciona para um nível de emissões projetados de 55 GtCO2.eq em 2030 (UNFCCC, 2015). Análises realizadas por Jones et al. (2016), Rogelj et al. (2016) e pelo Joint Research Centre da Comissão Europeia (EU-JRC, 2015) revelam que mesmo com a completa implementação das metas anunciadas pelos países por meio das suas iNDCs, elas tendem a elevar a temperatura média global até 2100 em torno de $3^{\circ} \mathrm{C}$ acima dos níveis pré-industriais. Reforçando que são necessárias propostas de mitigação mais fortes e profundas do que as atuais.

Determinados estudos já foram realizados para a avaliação da adequação da ambição da iNDC brasileira em relação aos objetivos do Acordo de Paris. O Climate Transparency (2015) analisou as iNDCs dos países do G-20 e classificou a iNDC do Brasil como "média", além de determinar que o país terá que fazer apenas "um pouco" de esforço adicional para alcançar a meta estabelecida. O Civil Society Review (2015) também analisou as iNDCs de diversos países com base nos critérios de "responsabilidade histórica" e "capacidade para realizar ações climáticas" e classificou a iNDC do Brasil como "injusta", pois a meta representa pouco mais de 2/3 (dois terços) da sua justa contribuição de acordo com a metodologia adotada no estudo. Araújo (2016) ao analisar o contexto interno do Brasil e a evolução da área de clima no país nos últimos anos, considera como "extremamente questionável" a ambição da meta da iNDC, sendo "quase como um retrocesso", visto que pode até permitir um aumento de emissões para os próximos anos.

Em contrapartida, alguns estudos consideram as metas de mitigação da iNDC brasileira ambiciosas, tais como Gregorio et al. (2016) e Pasqual et al. (2016). Costa (2016) considera a proposta da iNDC do Brasil como muito ambiciosa, pois o país pretende reduzir as emissões em um contexto de um esperado crescimento de PIB e renda per capita, aumento da população até 2040, além da situação de instabilidade política e pelo fato do Brasil ser um país em desenvolvimento e que ainda enfrenta o desafio de erradicação da pobreza de significante parcela da população. Rovere 
(2016) considera a meta proposta pelo Brasil como bem ambiciosa, sendo que somente a União Europeia apresentou uma proposta comparável à brasileira em termos de alta ambição. Mesmo considerando a iNDC brasileira ambiciosa, Rovere (2016) considera que o Brasil tem potencial de adotar medidas de mitigação factíveis compatíveis com um nível de emissão de 1 GtCO2.eq em 2030, podendo alcançar uma ambição bem maior que a atual iNDC.

Vale ressaltar os aspectos positivos da iNDC brasileira e do que o Brasil já conquistou na área climática: o Brasil possui a maior porcentagem de energias renováveis na sua matriz energética dentre os países do G-20 (CLIMATE TRANSPARENCY, 2015), teve êxito na redução do desmatamento na Amazônia no período de 2005-2009, não havendo outro caso semelhante de redução de GEE nessa magnitude por nenhum outro país por meio de políticas intencionadas de mitigação (VIOLA, FRANCHINI \& RIBEIRO, 2013) e de adotar uma meta de iNDC para o conjunto da sua economia, sendo o único grande país em desenvolvimento a adotar tal modalidade.

Outro ponto essencial é que o Brasil atinja a meta atual e as futuras por meio de políticas e ações intencionadas referentes a todos os setores e não por causa de fatores externos (recessão econômica, por exemplo) ou por causa de apenas um setor, caso das reduções de emissão do Brasil no passado recente oriundos da redução do desmatamento na Amazônia, enquanto os outros setores aumentaram suas emissões continuamente ao longo dos anos.

Pelas opiniões apresentadas de todas as partes e pela análise dos estudos sobre a ambição da iNDC brasileira, conclui-se que o país tem condições de aumentar sua ambição da meta global no curto prazo e ao mesmo tempo ser um objetivo factível, além de gerar benefícios ambientais, sociais e econômicos. Porém, o país ainda deverá superar vários desafios, principalmente econômicos, para transformar a meta proposta na sua atual NDC em políticas e programas visando a implementação de ações de mitigação que de fato coloquem as mudanças climáticas no cerne das principais estratégias de desenvolvimento do Brasil.

\section{CONCLUSÕES}

O Brasil se caracteriza por um país em desenvolvimento com aumento populacional e com questões básicas para melhorias. Com isso, a implementação da 
NDC brasileira representa uma grande oportunidade para o país criar um novo modelo de desenvolvimento que seja de baixa emissão de GEE.

O Brasil enfrentará vários desafios para implementar ações com o intuito de atingir a meta de mitigação proposta. Dentre os desafios, o Brasil deverá criar e aperfeiçoar os instrumentos econômicos e tributários e rever a governança climática que rege o tema no país, além de criar e aperfeiçoar novas políticas e programas de governo em um momento de instabilidade política.

Os setores de energia, florestas e mudança de uso do solo e a agropecuária deverão ter uma atenção especial por parte de todos os atores da sociedade para a formulação de políticas e ações que impactem direta ou indiretamente a mitigação de GEE.

Cada segmento pesquisado, apresenta argumentos válidos de acordo com a sua realidade para a ambição da NDC do Brasil. O país, porém, teria condições de aumentar suas ambições e ainda beneficiar diferentes áreas com um desenvolvimento mais sustentável.

\section{REFERÊNCIAS}

ARAÚJO, B. A. O regime internacional do clima e as implicações para o Brasil: o desafio do Acordo de Paris. Monografia (Bacharelado em Direito) - Universidade Federal do Ceará, Fortaleza, 2016. 96p.

BARDIN, I. Análise de conteúdo. Lisboa: Edições Setenta, 1994.

Brasil. Pretendida Contribuição Nacionalmente Determinada para a consecução do objetivo da Convenção-Quadro das Nações Unidas sobre Mudança do Clima. 10 p. 2015. Disponível em: http://www.itamaraty.gov.br/images/ed_desenvsust/BRASIL-iNDC portugues.pdf. Acesso em: 16 ago. 2016.

BRUYNE, P. Dinâmica da pesquisa em ciências sociais: os polos da prática metodológica. Rio de Janeiro: Francisco Alves, 1991.

CIVIL SOCIETY REVIEW. Fair shares: a civil society equity review of INDCs - Summary. 2015.

CLIMATE TRANSPARENCY. G20 climate action - a turning point?: an overview of climate mitigation action by the G20 countries - Summary. December, 2015.

COSTA, C. G. F. Fainess and equity implications for new governance mechanisms. 2016 Berlin Conference on Global Environmental Change. Berlin, 23-24, 2016.

EMPRESA DE PESQUISA ENERGÉTICA (EPE). Balanço energético nacional - ano base 2015. Relatório Síntese. Rio de Janeiro: EPE, 2016. 
EUROPEAN COMISSION - JOINT RESEARCH CENTRE (EU-JRC). Analysis of scenarios integrating the INDCs. JRC Policy Briefing. European Commission, Joint Research Centre. 2015.

GIDDENS, A. A política da mudança climática. Rio de Janeiro: Zahar, 2010.

DI GREGORIO, M.; FATORELLI, L.; PRAMOVA, E. MAY, P.; LOCATELLI, B.; BROCKHAUS, $M$. Integrating mitigation and adaptation in climate and land use policies in Brazil: a policy document analysis. (Centre for Climate Change Economics and Policy Working Paper No. 257. Sustainability Research Institute paper Noo. 94, Cifor Working paper n.194). Leeds/London, United Kingdom: CCCEP, SRI, Sustainability Research Institute, 2016.

GVces - CENTRO DE ESTUDOS EM SUSTENTABILIDADE DA FUNDAÇÃO GETÚLIO VARGAS. Contribuições para análise da viabilidade econômica da implementação do plano ABC e da INDC do Brasil. São Paulo: FGV, 2016.

INSTITUTO NACIONAL DE PESQUISAS ESPACIAIS (INPE). Nota técnica: INPE apresenta taxa de desmatamento consolidada do PRODES 2015. São José dos Campos, 29 de Setembro de 2016. 2016a. Disponível em:

http://www.obt.inpe.br/prodes/Prodes_Taxa2015_consolidada.pdf. Acesso em: 17 out. 2016.

INSTITUTO NACIONAL DE PESQUISAS ESPACIAIS (INPE). PRODES estima 7.898 km2 de desmatamento por corte raso na Amazônia em 2016. São José dos Campos, 29 de Novembro de 2016. 2016b. Disponível em http://www.inpe.br/noticias/noticia.php?Cod_Noticia=4344. Acesso em: 14 dez.2017.

INSTITUTO ESCOLHAS. Quanto o Brasil precisa investir para recuperar 12 milhões de hectares de florestas?. São Paulo, 2016.

INSTITUTO DE PESQUISA AMBIENTAL DA AMAZÔNIA (IPAM). Terras indígenas na Amazônia Brasileira: reservas de carbono e barreiras ao desmatamento. Brasília/DF: IPAM, 2015.

JONES, A.; JOHNSTON, E.; STERMAN, J.; SIEGEL, L. Deeper, earlier emissions cuts needed to reach Paris goals. Washington DC: Climate Interactive, 2016.

NEVES, J. L. Pesquisa qualitativa - características, usos e possibilidades. Caderno de pesquisa em administração, São Paulo, v.1, n.3, 1996.

OBSERVATÓRIO DO CLIMA. Análise da evolução das emissões de GEE no Brasil (1990-2012): documento síntese. São Paulo: Observatório do Clima, 2014.

OBSERVATÓRIO DO CLIMA. Análise das emissões de GEE no Brasil (1970-2014) e suas implicações para políticas públicas e a contribuição brasileira para o Acordo de Paris. São Paulo: Observatório do Clima, 2016.

PAINEL BRASILEIRO DE MUDANÇAS CLIMÁTICAS (PBMC). Impactos, Vulnerabilidades e Adaptação - Sumário Executivo do Grupo de Trabalho 2 ao Primeiro Relatório de Avaliação Nacional. Brasília, 2013.

PASQUAL, J.C.; ANAYA, R.P.; LEY, A.L.; ZUNIGA-TERAN, A.A.; LUGO, Y.P.; SANTELLANES, J.A.M. Implications and challenges for the energy sector in Brazil and Mex- 
ico to meet the carbon emission reductions committed in their INDC during the COP 21-CMP 11. Desenvolvimento e Meio Ambiente, v.37, p.31- 46, 2016.

ROGELJ, J.; ELZEN, M.; HöHNE, N.; FRANSEN, T.; FEKETE, H.; WINKLER, H.; SCHAEFFER, R.; SHA, F.; RIAHI, K.; MEINSHAUSEN, M. Paris agreement climate proposals need a boost to keep warming well below $2^{\circ} \mathrm{C}$. Nature, v. 534, n.30, 2016.

ROVERE, E. L. L. Transforming development pathways in Brazil: towards a low carbon economy. 2016 Berlin Conference on Global Environmental Change. Berlin, 23-24, 2016.

SILVA, C. R; GOBBI, B. C.; SIMÃO, A. A. O uso da análise de conteúdo como uma ferramenta para a pesquisa qualitativa: descrição e aplicação do método. Organizações rurais agroindustriais, Lavras, v.7, n.1, p.70-81, 2005.

TRIPODI, T., FELLIN; P.; MEYER, H. Análise da pesquisa social. Rio de Janeiro: Francisco Alves, 1981.

UNITED NATIONS FRAMEWORK CONVETION ON CLIMATE CHANGE (UNFCCC). The Paris Agreement. Paris, 2015. Disponível em

https://unfccc.int/resource/docs/2015/cop21/eng/l09r01.pdf. Acesso em: 15 fevereiro de 2018.

VIOLA, E.; FRANCHINI, M.; RIBEIRO, T. L. Sistema internacional de hegemonia conservadora: governança global e democracia na era da crise climática. São Paulo: Annablume, 2013.

WORLD RESOURCES INSTITUTE (WRI). Climate benefits, tenure costs: the economic case for securing indigenous land rights in the Amazon. Washington DC: WRI, 2016.

YOUNG, C. E. F. (coord.). Estudos e produção de subsídios técnicos para a construção de uma Política Nacional de Pagamentos por Serviços. Relatório Final. Instituto de Economia, UFRJ, Rio de Janeiro. Rio de Janeiro, p. 93. 2016. 